\section{TRANSPORTE URBANO NO MOTORIZADO: EL POTENCIAL DE LA BICICLETA EN LA CIUDAD DE TEMUCO ${ }^{1}$}

Verónica Xaviera Eltit Neumann²

\section{Resumen}

Las mutaciones sufridas por la ciudad de Temuco no están ajenas a las transformaciones sufridas por las ciudades intermedias a raíz de la globalización, en especial en la evolución de la movilidad espacial de sus habitantes. Por un lado, el aumento explosivo del parque automotriz, y por otro la modificación de formas de habitar, ha puesto en aprietos la estructura urbana, obligando a actualizar y a hacer más flexibles los instrumentos de planificación. Las principales consecuencias, en especial en Temuco, son una estructura vial inconexa, trunca y sin jerarquía, que junto con la ampliación de la taza de motorización (tanto pública como privada) ha provocado congestión y atochamiento.

\section{NON-MOTORIZED URBAN TRANSPORT: THE POTENTIAL OF BICYCLE IN TEMUCO'}

\author{
Verónica Xaviera Eltit Neumann²
}

\begin{abstract}
The transformations experienced by Temuco are not oblivious to the changes undergone by middle cities as a consequence of globalization, specifically the evolution of the spatial mobility of its inhabitants. The explosive growth of the vehicle fleet and changes in the ways of living present a challenge for the urban structure, leading up to the upgrade and deregulation of urban planning systems. The main consequence, especially for Temuco, is a disjointed, unfinished and without any hierarchy road structure, which, along the increase in the (public and private) motorization, have created traffic jams.
\end{abstract}


Bajo este escenario nacen análisis, reflexiones y propuestas en relación a nuevas formas de movilizarse, donde en esta oportunidad se desarrolla la idea de la bicicleta como una muy buena opción de transporte público no motorizado para la ciudad de Temuco, considerando las ventajas que la ciudad presenta para el desarrollo de esta forma de movilización.

Para lograr este objetivo es necesario el desarrollo de una infraestructura adecuada, que permita una circulación segura, expedita y rápida; pero también de políticas generales que fomenten y eduquen sobre el uso de la bicicleta en la ciudad.

PALABRAS CLAVES: BICICLETA, CICLOVÍAS, TRANSPORTE URBANO NO MOTORIZADO.

Fecha de recepción: 15.12.10

Fecha de aceptación: 10.06.11

1 Tesis para optar al grado de Magister en "Planificación Territo rial Ambiental" en el Instituto del Medio Ambiente de la Universidad de la Frontera de Temuco (2007).

2 Chile. Arquitecto. Magister en Planificación Territorial Ambiental por el Instituto de Estudios del Hábitat de la Facultad de Arquitectura y Construcción Universidad Autónoma de Chile. Avenida Alemania 01090, Temuco. Email:v.eltit@iehabitat.cl

154 revista invi № 72 / Agosto 2011 / Volumen № 26: 153-184
In this scenario, analyses, reflections and proposals are made regarding new forms of mobilization. This paper discusses the use of the bicycle as an option to public transport in Temuco by taking into account the advantages this city offers for this type of transport.

To achieve this goal, the development of proper infrastructure is needed so as to ensure not only safe, clear and fast circulation, but also general policies aimed at promoting the use of the bicycle in the city.

KEY WORDS: BICYCLE, CYCLE PATHS, NONMOTORIZED URBAN TRANSPORT

Received: 15.12.10

Accepted: 10.06.11

1 Thesis to apply to the MA in "Environmental Land Planning", Environment Institute, Universidad de la Frontera de Temuco (2007).

2 Chile. Architect, MA in Environmental Land Planning, Institute of Habitat Studies, Faculty of Architecture, Autonomous University of Chile. 


\section{Introducción}

El presenta texto ofrece un reflexión, por un lado general, sobre la bicicleta como transporte urbano no motorizado, y por otro sobre la infraestructura necesaria para su utilización en forma segura, expedita y rápida dentro de la ciudad.

La información utilizada nace básicamente de la investigación realizada el año 2007 para optar al grado de Magister en Planificación Territorial Ambiental $^{3}$. Para tal efecto, se utilizaron metodologías mixtas de investigación, tanto cuantitativas como cualitativas, en base a herramientas de recolección de información y análisis como entrevistas, encuestas para definir el perfil del usuario de la bicicleta en Temuco, caracterización de los viajes, origen y destino, fichas de registro (fotográfico y cartográfico), conteo de bicicletas en puntos relevantes de la ciudad, entre otros. Además, la investigación utiliza indicadores especialmente de movilidad como la encuesta Origen Destino desarrollada durante el año 2002 y actualizada el 2005. Estos antecedentes se han ido actualizando de manera parcializada, solo en directa relación a proyectos viales específicos.

Sin embargo, el objetivo de este texto es analizar las cualidades de la ciudad de Temuco para el uso

3 Tesis para optar al grado de Magister en “Planificación Territorial Ambiental" en el Instituto del Medio Ambiente de la Universidad de la Frontera de Temuco (2007). de la bicicleta y, en especial, los avances logrados y carencias aún presentes en relación a los temas diagnosticados en dicha investigación.

Este compilado se divide en cuatro capítulos. Parte desde reflexiones generales, donde se intenta entender las transformaciones de las ciudades intermedias, durante las últimas décadas, como originadores de conflictos urbanos que necesitan una mirada alternativa para dar múltiples respuestas a sus problemáticas. Dentro de este parámetro se considera a la bicicleta como una nueva (considerándola en forma masiva y empoderada) forma de movilidad espacial dentro de la estructura urbana. Se arriba, finalmente, al análisis de las necesidades de infraestructura especializada y políticas que motiven el uso de la bicicleta dentro de la ciudad.

\section{Las Nuevas Dinámicas de los Centros Urbanos}

\section{IMPACTO DE LA GLOBALIZACIÓN EN LOS CENTRO URBANOS}

En las últimas décadas el proceso de cambio de las ciudades se ha visto acelerado por las numerosas revoluciones tecnológicas que hemos vivido. Los procesos económicos han llevado a trasladar 
los centros de producción, que históricamente se ubicaban en las grandes ciudades del mundo desarrollado, a países menos desarrollados con costos de producción menor, leyes ambientales más flexibles y, sobre todo, con mano de obra de menor costo. Esto permitió la reducción del costo de los productos, haciendo más accesible la adquisición de bienes y servicios que, tradicionalmente, fueron exclusivos de algunas clases sociales.

Este fenómeno de desterritorialización en todo ámbito (ruptura de las fronteras físicas) ha transformado las ciudades, pasando de centros productivos colapsados por el hacinamiento, malas condiciones higiénicas y contaminación, a centros urbanos de servicios especializados e insertos en redes globalizadas interconectadas. En la actualidad, el móvil principal de la transformación de la ciudad moderna está teniendo su origen en lo que ocurre en el mundo. Para bien o para mal, los cambios en nuestras ciudades son derivados de la globalización ${ }^{4}$.

No obstante, la realidad del desarrollo de la vida urbana es que la gran mayoría de estos centros son de escala intermedia y que sus alcances y complejidades no les permiten insertarse como nodos articuladores de esta red globalizada. Sin embargo, estas ciudades pueden pasar a jugar un rol de ciudad intermedia en la red global, dependiendo de su posición y posibilidad de conexión a las grandes redes y

4 SASSEN Saskia, 2001. flujos. De esta manera, si bien las ciudades intermedias (la mayoría de las ciudades del planeta según la Cepal 2002) no son ciudades globales, si pueden pertenecer a este sistema de redes globalizadas ${ }^{5}$.

Sin embargo, la asociación a esta red globaliza$\mathrm{da}$ ha generado grandes transformaciones en los centros urbanos, por ejemplo la incorporación de nuevas formas de habitar la ciudad. La gente busca mayor seguridad y cercanía con la naturaleza, trasladando zonas residenciales a la periferia de la ciudad, en terrenos rurales, sin el equipamiento y servicios adecuados, generando una presión sobre los centros urbanos que obliga a extender la estructura vial, el transporte y la accesibilidad. Si a esto le sumamos la mayor facilidad para adquirir un automóvil, y como consecuencia el aumento del parque automotriz, el resultado son ciudades extensas, congestionadas y contaminadas.

La ciudad de Temuco, como fiel representante de las ciudades intermedias, no ha estado ajena a estos cambios. Durante los últimos 15 años las transformaciones en la estructura urbana, los modelos de habitar, desarrollo de servicios especializados y la imagen urbana de la ciudad reflejan el impacto de la globalización. Sin duda, Temuco está inserta en la red global, que la obliga a adaptarse a las modificaciones y enfrentar nuevos desafíos en la planificación y desarrollo de la infraestructura para 
dar respuesta a las nuevas exigencias del habitante moderno.

Es así como la ciudad, por un lado, se posiciona como la quinta ciudad a nivel nacional en relación a la concentración de población, después de Santiago, Valparaíso, Concepción y Antofagasta. Y por otro, su desarrollo constante en relación a la prestación de servicios especializados la ha posicionado en la estructura funcional de la macrozona sur (desde Los Ángeles hasta Chiloé), donde, por ejemplo, numerosas personas acceden a la ciudad de Temuco en busca de servicios médicos especializados, carreras universitarias de pregrado y post grado y comercio específico, entre otros.

Bajo esta lógica, Temuco actualmente se presenta como el principal centro urbano de la región de la Araucanía, concentrando las tensiones funcionales y estructurales en torno a una unipolaridad de servicios y equipamientos. Esta estructura regional ha definido el rol de la ciudad en base a la oferta entregada en forma diaria a la población flotante de todas las localidades cercanas a la ciudad, y a su vez, la demanda que este grupo humano exige sobre la estructura urbana de la misma.

A su vez, su crecimiento constante durante las últimas décadas ha modificado la morfología tradicional en torno al centro histórico comercial, generando una prolongación de éste hacia la zona poniente de la ciudad, sobre el corredor denominado "Av. Alemania". Esta nueva zona, principalmente comercial, ha sobrepasado la carga de ocupación del sector, en especial en relación a la conectividad y movilidad entre el centro y el sector poniente, de clara tendencia residencial. A esto se suma la carencia de conexiones norte-sur en toda la ciudad, provocando conflictos urbanos especialmente en relación a la movilidad.

\section{MOVILIDAD Y CONECTIVIDAD EN LAS CIUDADES}

Sin duda, uno de los aspectos más evidentes de las transformaciones que han sufrido las ciudades son la movilidad y la conectividad. Con la apertura de las fronteras se ha incrementado significativamente la movilidad de las personas, y por lo tanto la conectividad se ha transformado en un tema relevante tanto a nivel global (interconexión entre países) como local (dentro de las ciudades). Es así como tanto la estructura vial como el transporte público y privado se han debido adecuar a la rapidez de estos cambios. El problema del transporte y la circulación ha dejado de ser una situación que involucra a un grupo limitado de individuos. Se ha constituido en un problema social, al que se han sumado problemas técnicos reconocidos con urgencia de solución, creando una demanda que debe estar articulada por la sociedad en general ${ }^{6}$.

6 MORALES, Pedro, 2005 
En la sociedad actual se valoran el transporte (en especial el privado, como símbolo de estatus social) y la velocidad como bienes en sí mismos que conviene acrecentar. Por un lado, observamos que nuestra sociedad ha aumentado su movilidad, la gente se desplaza más, con mayor facilidad y además se han hecho dependientes de mayores insumos, que obtienen solo mediante el desplazamiento. Esto ha puesto el anhelo del automóvil propio como un símbolo de libertad y estatus. Esta movilidad motorizada privada incrementa la inequidad (pues una gran parte de la población no tiene acceso a ella, ya sea por edad, aspectos económicos, discapacidad, etc.), por lo tanto no es universal ni mucho menos sostenible. Este fenómeno pone en serios aprietos a la modesta estructura vial de las ciudades ${ }^{7}$.

Así, vemos cómo la ciudad, en forma paulatina, ha dejado de acoger al ciudadano, reemplazando zonas peatonales, plazas y parques por grandes centros comerciales y autopistas. El vehículo motorizado ha pasado a ser protagonista en las ciudades, obligando a los ciudadanos a incorporarse a este sistema.

Bajo este escenario, es importante redescubrir la ciudad buscando nuevas formas de apropiación, planificación y desarrollo. La congestión vehicular, sumada a un sistema vial que no responde a los cambios que han sufrido los centros urbanos, la contaminación atmosférica e incluso otros aspectos como la salud (sedentarismo, obesidad, cambios en la alimentación), nos llevan a pensar en nuevas formas de movilizarnos que nos generen alternativas para una vida urbana más armónica y sostenible.

Tal como se analizó anteriormente, el caso de Temuco no dista de esta realidad, donde la movilidad de la población en la ciudad también se ha incrementado notoriamente, ayudado por el aumento del parque automotriz, el que se extendió en más de un 31\% en solo 10 años, situación que probablemente se ha duplicado en la última década (tabla $\left.\mathrm{N}^{\circ} 1\right)$.

La ubicación geográfica equidistante a nivel regional de la ciudad de Temuco, deja aún más en evidencia la necesidad de movilidad, pues un alto porcentaje de la población de localidades cercanas a Temuco se desplaza diariamente hasta la ciudad para trabajar o abastecerse de los servicios que esta brinda. Esto ha generado un aumento en los recorridos urbanos e interurbanos para satisfacer las necesidades de movilidad, cada vez mayor, que requiere la población, al tiempo que presiona para la expansión y mejoramiento de la estructura vial existente, pues esta debe aumentar su capacidad y seguridad para los nuevos flujos.

7 CAPEL, Hernest, 2006. 
TABLA Nº1: INCREMENTO DEL PARQUE AUTOMOTRIZ EN TEMUCO

\begin{tabular}{l|l}
1982 & 0,012 Vehículos/Hab. \\
\cline { 2 - 2 } 2992 & 0,045 Vehículos/Hab. \\
\hline 2002 & 0,143 Vehículos/Hab. \\
\hline
\end{tabular}

FUENTE: INE, 2002

TABLA N². PARTICIÓN MODAL POR PERÍODO, AÑO 2005

\begin{tabular}{lllll}
\hline MODO & PUNTA MAÑANA & & \multicolumn{2}{l}{ FUERA DE PUNTA } \\
& VIAJES & PARTICIÓN & VIAJES & PARTICIÓN \\
\hline Auto Chofer & 12.630 & $12,2 \%$ & 8.469 & $13,6 \%$ \\
\hline Auto Acompañante & 11.426 & $11,0 \%$ & 3.974 & $6,4 \%$ \\
\hline Taxi Colectivo & 7.515 & $7,2 \%$ & 5.383 & $8,6 \%$ \\
\hline Caminata & 31.572 & $30,4 \%$ & 23.713 & $38,0 \%$ \\
\hline Bus & 38.264 & $36,9 \%$ & 20.109 & $32,3 \%$ \\
\hline Bicicleta & 2.346 & $2,3 \%$ & 699 & $1,1 \%$ \\
\hline TOTAL & 103.753 & $100,0 \%$ & 62.346 & $100,0 \%$ \\
\hline
\end{tabular}

FUENTE: SECTRA, Encuesta Origen Destino, 2005

TABLA N³. PARTICIÓN MODAL POR PROPÓSITO Y PERÍODO, AÑO 2005.

\begin{tabular}{lllllllllllll}
\hline MODO & \multicolumn{1}{l}{ TRABAJ0 } & \multicolumn{9}{c}{ ESTUDIO } & \multicolumn{3}{c}{ OTROS } \\
& AM & $\%$ & FP & $\%$ & AM & $\%$ & FP & $\%$ & AM & $\%$ & FP & $\%$ \\
\hline Auto Chofer & 8.117 & 23,3 & 2.592 & 31,5 & - & 0,0 & - & 0,0 & 4.508 & 23,9 & 5.869 & 12,1 \\
\hline Auto Acomp. & 3.433 & 9,9 & 415 & 5,0 & 6.695 & 13,4 & 634 & 11,9 & 1.289 & 6,8 & 2.909 & 6,0 \\
\hline Taxi Colect. & 4.136 & 11,9 & 1.036 & 12,6 & 1.668 & 3,3 & 156 & 2,9 & 1.691 & 9,0 & 4.171 & 8,6 \\
\hline Caminata & 6.246 & 17,9 & 1.562 & 19,0 & 18.416 & 36,9 & 2.099 & 39,4 & 6.891 & 36,5 & 20.034 & 41,1 \\
\hline Bus & 10.563 & 30,3 & 1.968 & 23,9 & 23.177 & 46,4 & 2.403 & 45,1 & 4.507 & 23,9 & 15.720 & 32,3 \\
\hline Bicicleta & 2.340 & 6,7 & 656 & 8,0 & - & 0,0 & 30 & 0,6 & - & 0,0 & - & 0,0 \\
\hline TOTAL & 34.835 & 100 & 8.228 & 100 & 49.956 & 100 & 5.323 & 100 & 18.88 & 100 & 48.702 & 100 \\
\hline
\end{tabular}

FUENTE: SECTRA, Encuesta Origen Destino 
TABLA N 4. GENERACIÓN Y ATRACCIÓN DE VIAJES POR MACROZONAS Y PERÍODO

\begin{tabular}{|c|c|c|c|c|c|c|c|c|}
\hline \multirow{2}{*}{$\begin{array}{l}\text { MACRO } \\
\text { ZONAS }\end{array}$} & \multicolumn{4}{|c|}{ PUNTA MAÑANA } & \multicolumn{4}{|c|}{ FUERA DE PUNTA } \\
\hline & $\begin{array}{l}\text { Viajes } \\
\text { Generados }\end{array}$ & $\begin{array}{l}\text { Viajes } \\
\text { Atraídos }\end{array}$ & $\begin{array}{l}\text { Generación } \\
\%\end{array}$ & $\begin{array}{l}\text { Atracción } \\
\%\end{array}$ & $\begin{array}{l}\text { Viajes } \\
\text { Generados }\end{array}$ & $\begin{array}{l}\text { Viajes } \\
\text { Atraídos }\end{array}$ & $\begin{array}{l}\text { Genera } \\
\%\end{array}$ & $\begin{array}{l}\text { Atracción } \\
\%\end{array}$ \\
\hline Centro & 5.472 & 34.224 & 5 & 33 & 15.916 & 23.883 & 30 & 38 \\
\hline P. Valdivia & 16.803 & 9.466 & 16 & 9 & 5.282 & 6.228 & 10 & 10 \\
\hline Poniente & 24.302 & 21.434 & 23 & 21 & 10.626 & 10.320 & 20 & 17 \\
\hline P. Nuevo & 24.175 & 20.435 & 23 & 20 & 10.636 & 10.326 & 20 & 17 \\
\hline P. Casas & 13.047 & 8.219 & 13 & 8 & 2.833 & 4.339 & 5 & 7 \\
\hline Amanecer & 19.953 & 9.976 & 19 & 10 & 8.072 & 7.250 & 15 & 12 \\
\hline TOTAL & 103.753 & 103.753 & 100 & 100 & 53.365 & 62.346 & 100 & 100 \\
\hline
\end{tabular}

FUENTE: SECTRA, Encuesta Origen Destino

TABLA N5. DISTANCIAS MÁXIMAS ENTRE SECTORES DE TEMUCO

\begin{tabular}{|c|c|c|c|}
\hline SECTOR ORIGEN & SECTOR DESTINO & DISTANCIA MÁXIMA & RECORRIDO PROMEDIO \\
\hline Sector Poniente & & 4.2 Km. Aprox. & $2.3 \mathrm{Km}$. Aprox. \\
\hline Acceso Norte & & $4.5 \mathrm{Km}$. Aprox. & 1.9 Km. Aprox. \\
\hline Acceso Sur & CENTRO D & 4.2 Km. Aprox. & $3.6 \mathrm{Km}$. Aprox. \\
\hline Acceso desde Chol Chol & & 4.6 Km. Aprox. & 2.9 Km. Aprox. \\
\hline Localidad de El Carmen & & 7.0 Km. Aprox. & 7.0 Km. Aprox. \\
\hline DISTANCIAS PROMEDIO & & $4.9 \mathrm{Km}$. Aprox & 3.5 Km. Aprox. \\
\hline
\end{tabular}

FUENTE: Tesis Magister, Universidad de la Frontera, 2007 actualizada al 2010.

TABLA Nº. COMPARACIÓN DE ALCANCES DE LA BICICLETA

\begin{tabular}{llll} 
Modo de Desplazamiento & Velocidad Media & Distancia Recorrida en 10 min. & Área de Influencia \\
Peatonal & $5 \mathrm{Km} / \mathrm{H}$ & $0.6 \mathrm{Km}$. & $2 \mathrm{Km} 2$ \\
\hline Bicicleta & $20 \mathrm{Km} / \mathrm{H}$ & $3.2 \mathrm{Km}$. & $32 \mathrm{Km} 2$ \\
\hline
\end{tabular}

FUENTE: Manual Fomento de la Bicicleta, Unión Europea, 2002. 
TABLA N²7. VIAJES EN BICICLETA POR PERÍODO Y DIARIO, POR RANGO DE INGRESO

\begin{tabular}{llll}
\hline ESTRAT0 & RANG0 INGRESO MENSUAL & VIAJES & TOTAL \\
Bajo & $<=200,000$ & 6.858 & $48 \%$ \\
\hline Medio & $200,000-600,000$ & 7.152 & $50 \%$ \\
\hline Alto & $>600,000$ & 287 & $2 \%$ \\
\hline TOTAL & 14.297 & $100 \%$ \\
\hline
\end{tabular}

FUENTE: SECTRA, Encuesta Origen Destino, 2002 actualizada el 2005

\section{TABLA N8. CICLOVÍAS EXISTENTES EN TEMUCO}

\begin{tabular}{|c|c|c|c|c|}
\hline EJE & $\begin{array}{l}\text { TRAMO } \\
\text { DESDE }\end{array}$ & HASTA & TIPOLOGÍA & LARGO ML. \\
\hline Av. Recabarren & Fco. Salazar & Javiera Carrera & Exclusiva & 1.463 \\
\hline Av. Los Poetas & Prat & Las Quilas & Exclusiva & 1.643 \\
\hline Av. Balmaceda & Caupolicán & Antonio Matta & Exclusiva & 619 \\
\hline Rudecindo Ortega & Nahuelbuta & Unión Norte & Exclusiva & 1.785 \\
\hline Av. Simón Bolívar & Uruguay & Límite Urbano & Exclusiva & 4.005 \\
\hline Rudecindo Ortega & Unión Norte & Ruta 5 Sur & Incorporada & 7.560 \\
\hline Línea Férrea & Caupolicán & Gral. Mackenna & Exclusiva & 1.610 \\
\hline Línea Férrea & Caupolicán & Uruguay & Exclusiva & 1.591 \\
\hline Zenteno & Barros Arana & Balmaceda & Compartida & 833 \\
\hline Martín Lutero & Los Ganaderos & Gabriela Mistral & Exclusiva & 1.493 \\
\hline Gral. Mackenna & O’Higgins & Barros Arana & Compartida & 93 \\
\hline Av. Costanera & Barros Arana & Los Poetas & Exclusiva & 2.090 \\
\hline Los Poetas & Av. Costanera & Quidel & Exclusiva & 577 \\
\hline Av. Huérfanos & Barros Arana & Rudecindo Ortega & Exclusiva & 35.892819 \\
\hline TOTAL & & & & 26.181 \\
\hline
\end{tabular}

FUENTE: Eltit, Verónica. 2007 
TABLA Nº. CICLOVÍAS PROPUESTAS POR INSTITUCIONES PÚBLICAS

\begin{tabular}{|c|c|c|c|c|}
\hline EJE & $\begin{array}{l}\text { TRAMO } \\
\text { DESDE }\end{array}$ & HASTA & TIPOLOGÍA & LARGO ML. \\
\hline \multicolumn{5}{|c|}{ CICLOVÍAS PROYECTADAS POR LA MUNICIPALIDAD DE TEMUCO } \\
\hline Simón Bolívar & Puntilla del Maipo & Labranza & Exclusiva & 8.000 \\
\hline Javiera Carrera & Pedro de Valdivia & Gabriela Mistral & Incorporada & 1.591 \\
\hline Nahuelbuta & Gral. Cruz & Aldunate & Exclusiva & 5.024 \\
\hline SUBTOTAL & & & & 14.615 \\
\hline \multicolumn{5}{|c|}{ CICLOVÍAS PROYECTADAS POR EL M.0.P. } \\
\hline Av. Recabarren & Javiera Carrera & Puntilla del Maipo & Exclusiva & 1.883 \\
\hline SUBTOTAL & & & & 1.883 \\
\hline \multicolumn{5}{|c|}{ CICLOVÍAS PROYECTADAS POR EL SERVIU } \\
\hline Barros Arana & Av. Pinto & Gral. Mackenna & Compartida & 855 \\
\hline SUBTOTAL & & & & 855 \\
\hline \multicolumn{5}{|c|}{ CICLOVÍAS PROYECTADAS POR SECTRA } \\
\hline Pedro de Valdivia & Prieto Norte & Javiera Carrera & Exclusiva & 4.309 \\
\hline Javiera Carrera & Gabriela Mistral & Recabarren & Exclusiva & 3.128 \\
\hline Av. Balmaceda & Caupolicán & Prieto Norte & Exclusiva & 1.073 \\
\hline Av. Prieto Norte & Monte Ararat & Av. Alemania & Exclusiva & 1.205 \\
\hline Hoschtetter & Av. Alemania & Pablo Neruda & Exclusiva & 1.854 \\
\hline Pablo Neruda & Hoschtetter & Javiera Carrera & Exclusiva & 1.612 \\
\hline Uruguay & Pablo Neruda & Montevideo & Incorporada & 804 \\
\hline Montevideo & Uruguay & Fco. Salazar & Incorporada & 300 \\
\hline Fco. Salazar & Caupolicán & Recabarren & Incorporada & 1.555 \\
\hline Av. Pinto & Balmaceda & Rudecindo Ortega & Exclusiva & 618 \\
\hline Rudecindo Ortega & Av. Pinto & Ziem & Exclusiva & 558 \\
\hline Ziem & Rudecindo Ortega & Valparaíso & Incorporada & 432 \\
\hline Valparaíso & Ziem & Caupolicán & Exclusiva & 339 \\
\hline Caupolicán & Valparaíso & Nahuelbuta & Incorporada & 370 \\
\hline Caupolicán & Fco. Salazar & Imperial & Incorporada & 383 \\
\hline SUBTOTAL & & & & 18.539 \\
\hline TOTAL & & & & 35.892 \\
\hline
\end{tabular}

FUENTE: Eltit, Verónica. 2007

162 revista invi № 72 / Agosto 2011 / Volumen № 26: 153-184 


\section{GRÁFICO Nº 1}

\section{MODALIDAD DE TRASLADO. PERÍODO PUNTA}

\begin{tabular}{lll}
\hline MODO & $\%$ & $\mathrm{~N}^{\mathbf{0}}$ \\
\hline AUTO CHOFER & 12 & 12.630 \\
\hline AUTO ACOMPAÑANTE & 11 & 11.426 \\
\hline TAXI COLECTIVO & 7 & 7.515 \\
\hline CAMINATA & 31 & 31.572 \\
\hline BUS & 37 & 38.264 \\
\hline BICICLETA & 2 & 2.346 \\
\hline
\end{tabular}

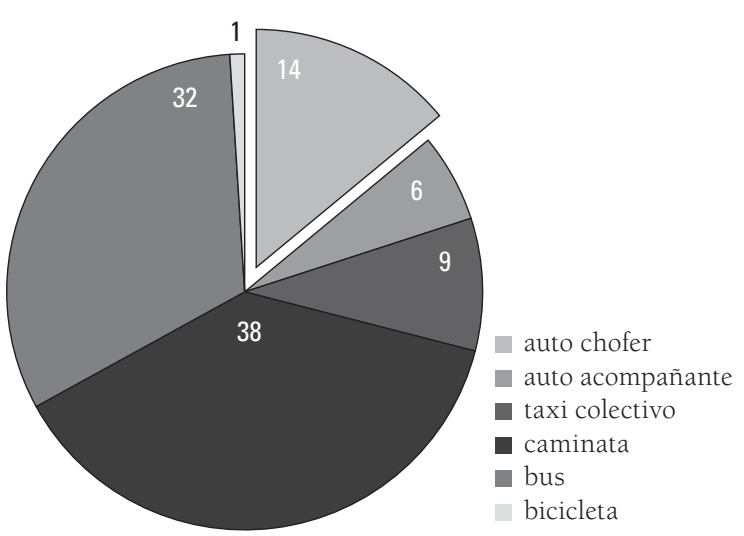

FUENTE: SECTRA, Encuesta Origen Destino, 2005

\section{MODALIDAD DE TRASLADO. PERIODO FUERA DE} PUNTA

\begin{tabular}{lll} 
MODO & $\%$ & $\mathrm{~N}^{\mathbf{0}}$ \\
\hline AUTO CHOFER & 14 & 8.469 \\
\hline AUTO ACOMPAÑANTE & 6 & 3.974 \\
\hline TAXI COLECTIVO & 9 & 5.383 \\
\hline CAMINATA & 38 & 23.713 \\
\hline BUS & 32 & 20.109 \\
\hline BICICLETA & 1 & 699 \\
\hline
\end{tabular}

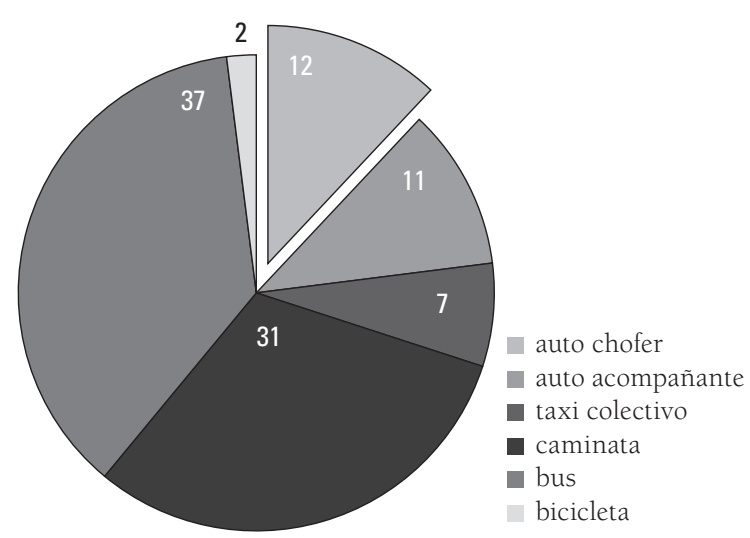


GRÁFICO N². GENERACIÓN Y ATRACCIÓN DE VIAJES POR MACROZONAS. PERÍODO PUNTA MAÑANA

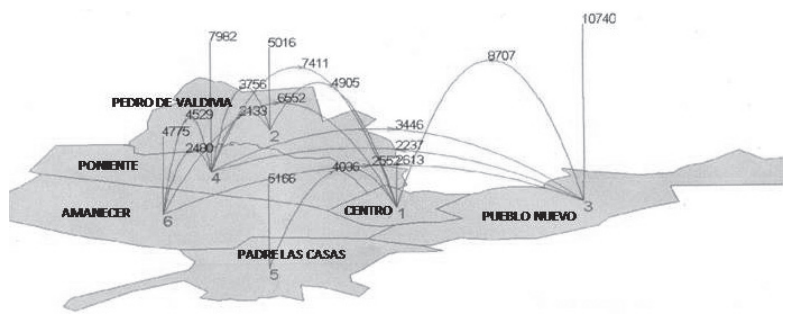

FUENTE: SECTRA, Encuesta Origen Destino, 2005

\section{GRÁFICO N³. GENERACIÓN Y ATRACCIÓN DE} VIAJES POR MACROZONAS. PERÍODO FUERA DE PUNTA

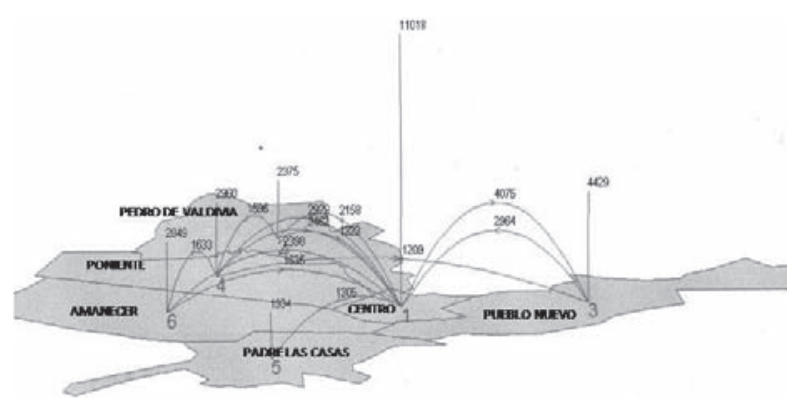

GRÁFICO N²4. INFLUENCIA DE LAS CONDICIONES ATMOSFÉRICAS SOBRE EL USO DE LA BICICLETA

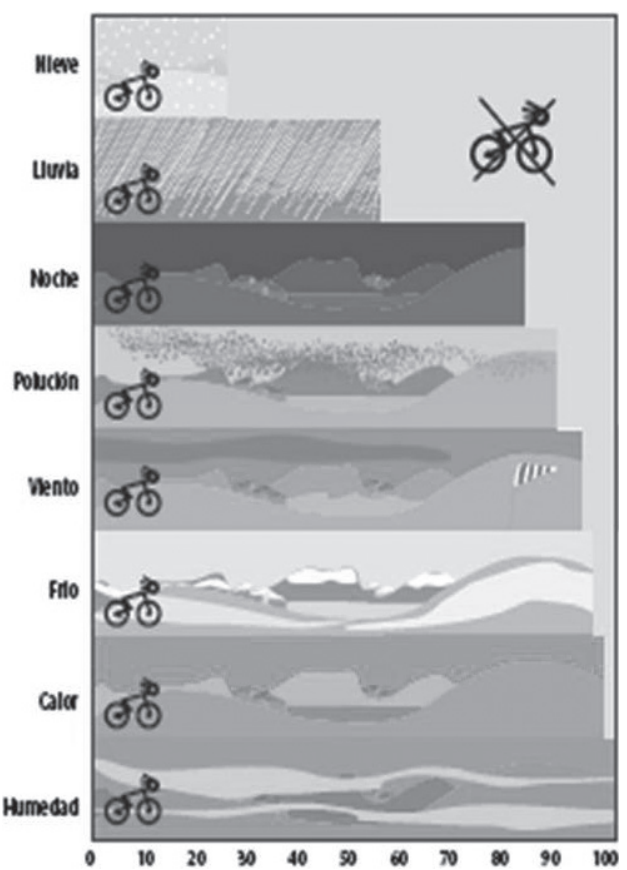

FUENTE: Manual Fomento de la Bicicleta, Unión Europea, 2002.

FUENTE: SECTRA, Encuesta Origen Destino, 2005 
GRÁFICO N ${ }^{\circ} 5$. CARACTERIZACIÓN DEL USUARIO DE BICICLETA EN TEMUCO

\begin{tabular}{ll} 
SEXO & $\mathrm{N}^{0}$ \\
HOMBRE & 425 \\
\hline MUJER & 52 \\
\hline
\end{tabular}

\begin{tabular}{l|l|l}
\hline & \multicolumn{1}{l}{ EDAD } & \multicolumn{2}{l}{$N^{0}$} \\
\hline \multirow{4}{*}{ FEMENINO } & $0-15$ & 0 \\
\cline { 2 - 3 } & $16-20$ & 7 \\
\cline { 2 - 3 } & $21-40$ & 29 \\
\cline { 2 - 3 } MASCULINO & $41 \mathrm{Y}$ más & 11 \\
\hline \multirow{4}{*}{} & $0-15$ & 4 \\
\cline { 2 - 3 } & $16-20$ & 22 \\
\cline { 2 - 3 } & $21-40$ & 202 \\
\cline { 2 - 3 } & $41 \mathrm{Y}$ más & 181 \\
\hline
\end{tabular}

\section{NIVEL}

\begin{tabular}{ll} 
No Contestó & 4 \\
\hline $1^{\circ}$ a $8^{\circ}$ Básico & 163 \\
\hline I a IV Medio & 254 \\
\hline Sup. Incompleta & 49 \\
\hline Sup. Completa & 7 \\
\hline
\end{tabular}

\begin{tabular}{llll} 
ESTRAT0 & $\begin{array}{l}\text { RANGO INGRESO } \\
\text { MENSUAL }\end{array}$ & VIAJES & TOTAL \\
Bajo & $<=200,000$ & 6.858 & $48 \%$ \\
\hline Medio & $200,000-600,000$ & 7.152 & $50 \%$ \\
\hline Alto & $>600,000$ & 287 & $2 \%$ \\
\hline TOTAL & & 14.297 & $100 \%$ \\
\hline
\end{tabular}
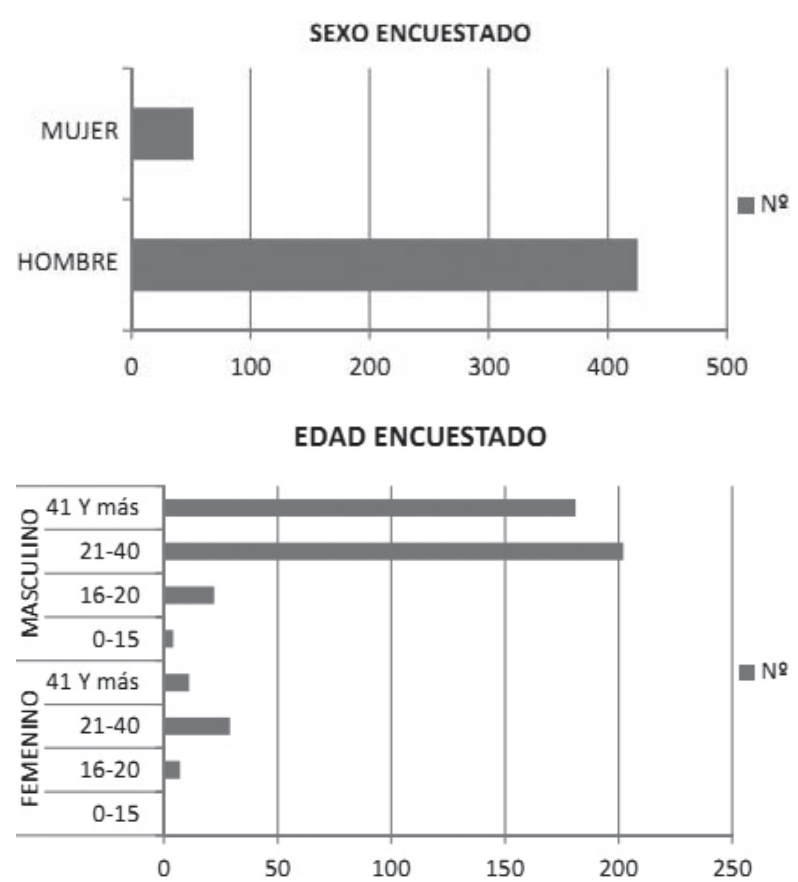

NIVEL EDUCACIONAL ENCUESTADO

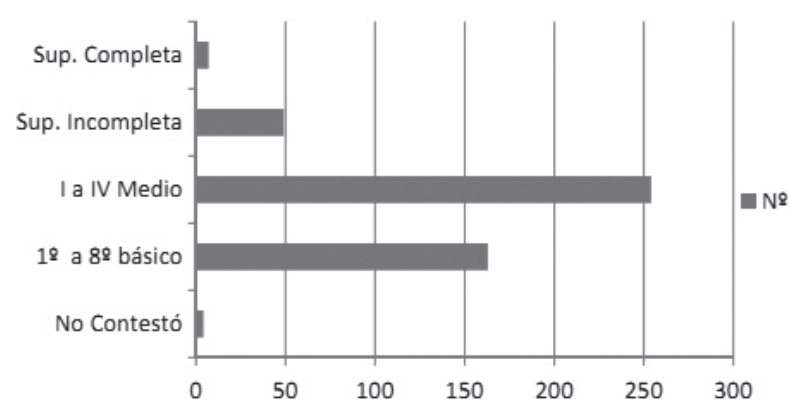

revista invi № 72 / Agosto 2011 / Volumen № 26: 153-184 165 
GRÁFICO Nº6. CARACTERIZACIÓN DE LOS VIAJES EN BICICLETA

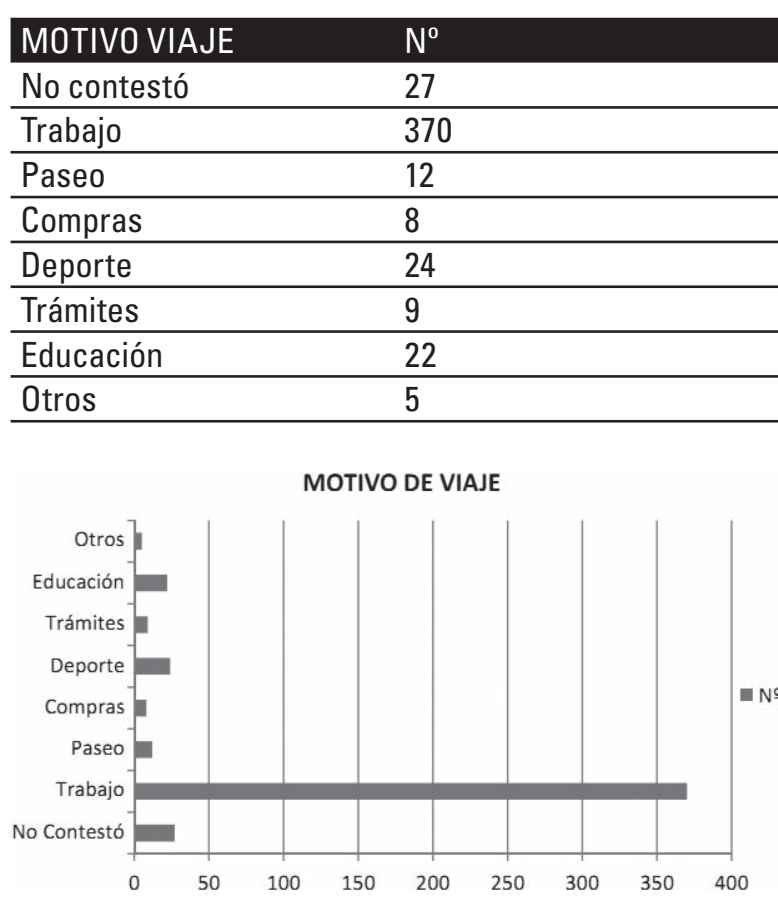

FUENTE: Eltit, Verónica. 2007
166 revista invi № 72 / Agosto 2011 / Volumen No 26: 153-184
GRÁFICO Nº7. HORARIOS PUNTA DE VIAJE EN BICICLETA

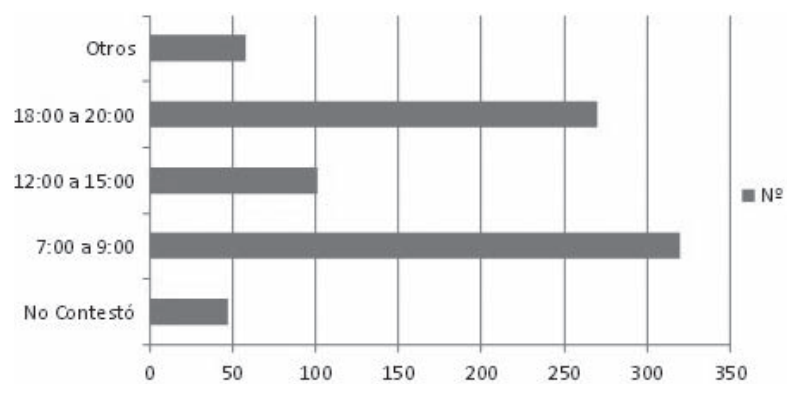

\begin{tabular}{ll} 
HORA & $\mathrm{N}^{0}$ \\
\hline No contestó & 47 \\
\hline 7:00 a 9:00 & 320 \\
\hline 12:00 a 15:00 & 101 \\
\hline 18:00 a 20:00 & 270 \\
\hline Otros & 58 \\
\hline
\end{tabular}

FUENTE: Eltit, Verónica. 2007

GRÁFICO N8. RELACIÓN DISTANCIA VEHÍCULO V/S CICLISTAS

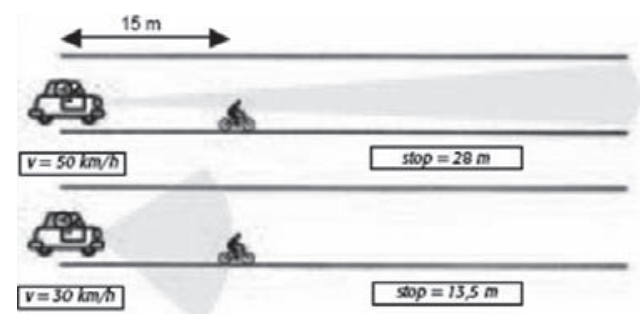

FUENTE: Manual Fomento de la Bicicleta, Unión Europea, 1995.
ARTÍCULO: Transporte urbano no motorizado: el potencial de la bicicleta en la ciudad de Temuco / Verónica Xaviera Eltit Neumann 
Dentro de la ciudad de Temuco la mayoría de las zonas son de usos homogéneos, por ejemplo la zona poniente es preferentemente residencial y la zona céntrica es de servicios y comercio. Esto obliga a las persona a trasladarse diariamente para acceder a trabajos, comercio y educación.

Por ejemplo, si analizamos la partición modal del transporte urbano de Temuco (tabla $N^{\circ} 2$ ), vemos que más del $60 \%$ de la población se traslada en vehículos motorizados, del cual el $41 \%$ lo hace en locomoción pública.

Sin embargo, esto genera congestión vehicular (especialmente en horas punta), necesidad de espacio para estacionamientos y contaminación, entre otros.

Pero por otro lado, al revisar la modalidad de traslado dentro de la ciudad (gráfico $N^{\circ} 1$ y 2 ) destaca que casi un $40 \%$ de la población de Temuco desarrolla sus trayectos cotidianos caminando, lo que reafirma la idea de que Temuco es aún una ciudad relativamente pequeña, con una escala adecuada para el desarrollo de desplazamientos en modos alternativos, pues la mayoría de los trayectos son menores a $5 \mathrm{Km}$.

De estos viajes dentro de la ciudad (tabla $N^{\circ} 3$ ), observaremos que el principal es el estudio (50\% de los viajes) y nuevamente el modo es caminando.

Esta información destaca nuevamente un público objetivo por edad y estado físico que propicia el desplazamiento no motorizado dentro de la ciudad de Temuco. No obstante, el automóvil ha adquirido un marcado protagonismo en Temuco y en la mayoría de las ciudades, desplazando a los peatones, pues la exigencia de mejorar y ampliar la estructura vial ha ido en desmedro de los espacios públicos peatonales, transformando las calles en espacios de circulación enrejados y limitados.

Por otro lado, al analizar el origen y destino de estos viajes (tabla $\mathrm{N}^{\circ}$ 4) se observa la gran concentración de personas que viajan desde la zona Poniente y Pueblo Nuevo, principalmente con usos residenciales, al Centro de la ciudad como zona de servicios, reafirmando la carencia de usos mixtos en los distintos sectores de Temuco.

Obviamente, esto provoca congestión y colapso de la estructura vial del sector fundacional de la ciudad, la que es más dura al cambio por la organización morfológica, funcional y valor de suelo. Este fenómeno ha provocando la aparición de nuevos servicios de apoyo al traslado urbano, como estacionamientos subterráneos bajo las principales plazas del centro de la ciudad, restricción vehicular por numeración de patentes a vehículos utilizados para el transporte de pasajeros (colectivos, principalmente) y extensión del centro de servicios y comercial hacia la periferia de la zona fundacional (sector Avenida Alemania) que permite, por espacio y valor de suelo, el desarrollo de proyectos que acojan estas necesidades, principalmente de estacionamientos. 
Es interesante destacar en relación a la información otorgada por la encuesta Origen Destino (realizada el año 2002 y actualizada el año 2005) que la única zona que genera y atrae viajes internos es la zona Poniente de la ciudad (gráfico No 2 y 3); esto responde a la existencia de diversos servicios, especialmente en la zona de Avenida Alemania (comercio, educación, salud, etc.), a diferencia de zonas como Amanecer y Pedro de Valdivia, que se ven obligados a desplazarse diariamente al centro.

\section{Ciudad y Bicicleta}

\section{ESCALA URBANA, MOVILIDAD Y TRANSPORTE NO MOTORIZADO}

En la mayoría de las ciudades, al menos el 30\% de los trayectos realizados en auto cubren distancias inferiores a $3 \mathrm{Km}$., y el $50 \%$, de menos de $5 \mathrm{~km}^{8}$.

Si traspolamos esta estadística a las distancias promedio de la ciudad de Temuco, tenemos que:

Las distancias promedio de la ciudad no son diferentes de la realidad de la mayoría de las ciudades intermedias no dispersas, donde los traslados promedios generalmente no superan los $3 \mathrm{~km}$. Incluso, las localidades aledañas a Temuco, que conforman polos residenciales como el sector El Carmen o La-

8 Community Research and Development Information Service, 2002 branza, aún logran consolidarse dentro del sistema de movilidad espacial de la ciudad, con distancias intermedias que permiten todavía un desplazamiento en diversas formas de movilización.

Claramente, la escala de la ciudad tanto por distancias como por concentración urbana propicia el desplazamiento y movilidad de la población de diversas maneras, siempre y cuando el desarrollo de la infraestructura sea planificado para promover la diversificación de modos de transporte, en especial aquellos no contaminantes y que colaboren a la descongestión de la ciudad.

\section{CIUDAD Y BICICLETA}

Las mejoras técnicas han hecho de la bicicleta un vehículo moderno, cómodo y eficaz. Además de no contaminar y ser silenciosa, económica, discreta y accesible a todos los miembros de la familia, la bicicleta resulta, sobre todo, más rápida que el auto en trayectos urbanos de corta distancia como lo demuestra la tabla No 6 (5 km., e incluso más, a medida que aumenta la congestión del tráfico).

Así, el potencial de la bicicleta como transporte urbano no es despreciable, ni para los desplazamientos cotidianos hasta el colegio o el trabajo, ni para otros tipos de desplazamiento restante (compras, servicios, ocio, actividades sociales, etc.). Es- 
tudios internacionales ${ }^{9}$ han puesto de manifiesto que la elección de un modo de transporte como la bicicleta en las ciudades depende tanto de factores subjetivos (imagen de marca, aceptabilidad social, sentimiento de inseguridad, reconocimiento de la bicicleta como medio de transporte adulto, etc.), como de factores objetivos (rapidez, topografía, clima, seguridad, aspectos prácticos). Entre los factores objetivos desfavorables del uso de la bicicleta en la ciudad solo resultan realmente disuasorios la existencia de un gran número de fuertes pendientes (superiores al 6-8 \% a lo largo de varias decenas de metros) o la persistencia de viento, lluvia o fuertes calores.

En el caso de Temuco, la geografía es un elemento a favor, ya que la ciudad se encuentra localizada en el valle, bordeando el cajón del río Cautín, donde solo un menor porcentaje de la ciudad se encuentra en zonas con pendientes superiores al 6\%, tal como lo muestra el mapa $\mathrm{N}^{\circ} 1$.

Bajo este escenario, en términos generales, las condiciones geográficas y climáticas favorables (como lo muestra el gráfico $\mathrm{N}^{\circ}$ 4) son un buen complemento a una política de movilidad urbana integral, donde la bicicleta adquiera protagonismo en la ciudad, siendo perfectamente posible alcanzar un nivel de utilización de esta del 20 al $25 \%$ en ciudades de 50.000 a 500.000 habitantes (consideradas

9 CREATING a chain reaction, 2004 como ciudades intermedias). Incluso, actualmente las ciudades más eficaces en países como Dinamarca y Holanda alcanzan índices de utilización de la bicicleta superior al 40\% ${ }^{10}$.

Sin duda Temuco se encuentra dentro de este grupo de ciudades intermedias (245.347 habitantes según el Censo de 2002) con el potencial de promoción del uso de la bicicleta como medio de transporte urbano, considerando que no tiene grandes pendientes, clima templado frío que presenta mejores condiciones que las de los Países Bajos, donde hay largos meses con nieve, distancias promedio no superiores a $3 \mathrm{~km}$. y más del 32\% de la población actualmente desplazándose hacia su trabajo o lugar de estudio en medios de transporte no motorizados.

Sin embargo, actualmente en Temuco el traslado en bicicleta solo alcanza el 2,3\% del total de traslados dentro de la ciudad según la encuesta Origen Destino del año 2005. Las principales razones son los meses de lluvia y, en especial, el riesgo que implica circular en bicicleta, tanto por los robos como por la falta de conciencia de los automovilistas ${ }^{11}$. Además, la bicicleta ha adquirido una imagen de bajo estatus social que debe ser revertido, vinculado principalmente a que la mayoría de sus usuarios pertenecen al rango categorizado como bajo en ingresos, tal como lo indica la tabla $\mathrm{N}^{\circ} 7$.

\section{BOTMA Y PAPENDRECH, 1991}

11 AKIKI, Natalia, 2006. 
Así mismo, al analizar el perfil del usuario de la bicicleta en Temuco, destaca que la mayoría son hombres (89\% de los encuestados ${ }^{12}$ ), entre $21 \mathrm{y}$ 40 años $\left(52,7 \%\right.$ de los encuestados $\left.{ }^{13}\right)$, sin estudios superiores (53,2\% enseñanza media y $34,1 \%$ enseñanza básica ${ }^{14}$ ) y con ingresos medios o bajos.

Además, si esta información se contrasta con la localización y concentración de bicicletas por manzana en la ciudad, se entiende que conforme aumenta la distancia hacia el área de borde se aprecia un aumento en el número de bicicletas por manzana.

Por otro lado, el principal motivo del uso de la bicicleta en Temuco es para trasladarse al trabajo como lo muestra el gráfico $\mathrm{N}^{\circ} 6$.

El sector de origen de estos viajes es principalmente la zona de Pedro de Valdivia (a pesar de las fuertes pendientes, que pueden llegar a superar en algunos tramos el 15\%) y Pueblo Nuevo, coincidentemente con los sectores de más bajos ingresos en la ciudad. Y los principales destinos son el centro y el sector poniente, donde se localizan los servicios, equipamientos y las principales fuentes de trabajo.

Según la estadística presentada por Sectra en la encuesta Origen Destino desarrollada para la ciudad de Temuco el año 2005, se puede inferir que el retorno a las zonas de residencias es en horarios diferenciados, o sea, la mayoría de los usuarios se trasladan a sus destinos (trabajo, estudio, trámites, etc.) durante la mañana en un horario similar (entre las 7:30 y las 9:30 hrs.), pero, el regreso es en un horario más amplio, desde las 15:30 hrs. en adelante, dependiendo el motivo del viaje.

En base al diagnóstico aquí presentado sobre la situación del uso de la bicicleta y el perfil de sus usuario en la ciudad de Temuco, las instituciones y organizaciones de la ciudad y la región se han abocado a desarrollar diversas iniciativas en esta línea. Dentro de las más destacadas está el Plan Maestro de Ciclovías de la Ciudad de Temuco, liderado por el Municipio, que además está desarrollando el "Programa de Promoción del Uso de la Bicicleta y Ciclovías de Temuco", a implementarse con un modelo de gestión conjunto con las empresas privadas regionales en el ámbito del traslado por trabajo, recreación o deporte. Además, como forma de aproximación, se han organizado varias cicletadas familiares en conjunto con universidades regionales, donde se recorre la ciudad acercando al potencial usuario a las zonas más seguras de movilización en bicicleta.

Estos programas y planes se basan en la experiencia de ciudades que han aplicado el "fomento" para

\footnotetext{
12 ELTIT, Verónica, 2007.

13 Ibidem

14 Ibidem
}

170 revista invi № 72 / Agosto 2011 / Volumen № 26: 153-184
ARTíCULO: Transporte urbano no motorizado: el potencial de la bicicleta en la ciudad de Temuco /

Verónica Xaviera Eltit Neumann 
ciclistas, donde se ha probado la eficacia de estas medidas para estimular el uso de la bicicleta y los beneficios que representa para la seguridad. El valor de la percepción de seguridad por parte de los ciclistas es básico para el fomento de su uso.

Se considera que la moderación de la velocidad tiene un efecto muy sensible sobre la percepción del espacio urbano por los peatones y los ciclistas (el tráfico lento es menos estresante que el tráfico rápido). Debido a esto parte de los últimos estudios en desarrollo para la ciudad tienen relación con la posibilidad de la implementación de zonas de restricción de velocidad, para fomentar el uso de la bicicleta en la ciudad. Al respecto, se considera que en la ciudad las reducciones de velocidad son numerosas y las ocasiones de alcanzar la velocidad máxima permitida son limitadas, ya sea por la presencia de semáforos, maniobras de estacionamiento de otros conductores, cruces de peatones, paradas en doble fila, autobuses que salen de las paradas, entre otros. La circulación máxima a 30 $\mathrm{km} . / \mathrm{h}$. resulta apenas más lenta que a $50 \mathrm{~km} . / \mathrm{h}$. (se necesitan 4 minutos para recorrer $2 \mathrm{~km}$. a 30 $\mathrm{km} . / \mathrm{h}$., sin obstáculos, frente a 3 minutos a 40 km./h. y 2 1/2 minutos a $50 \mathrm{~km} . / \mathrm{h} .{ }^{15}$

Por otro lado, el adecuado diseño de la vías para ciclistas, ya sea integradas o segregadas, incide directamente en el factor seguridad. Si las ciclovías

15 Manual de Fomento del Uso de la Bicicleta en la Unión Europea, 1995. están incorrectamente diseñadas, dan una falsa impresión de seguridad, tanto a los automovilistas como a los ciclistas (al sentirse cada uno "en su terreno" y con derecho a imponer el respeto de la norma al otro, con riesgo de confusión de las prioridades, implícitas y explícitas). La realización de estas pistas solo resulta realista si se dispone de medios para una planificación rigurosa (pues, en caso de error a la hora de elegir, las pistas no se utilizan, perdiéndose el espacio que tienen reservado y las inversiones realizadas) ${ }^{16}$.

Es así como, además del desarrollo de infraestructura para bicicletas (ciclovías) dentro de la ciudad de Temuco, se están analizando medidas de más corto plazo y menor inversión, como ciclobandas en calles donde al eliminar los estacionamientos laterales se podría contar con el espacio adecuado para la implementación de la pista segregada por tachas demarcadoras, como es el caso de avenida O’Higgins y San Martín, que conectan de forma directa el centro con la zona poniente de la ciudad.

\section{LA BICICLETA Y LOS BENEFICIOS PARA LA SALUD}

En realidad, para muchas personas la bicicleta constituye el único medio de hacer regularmente un ejercicio moderado sin necesidad de cambiar los hábitos cotidianos.

16 BOEING, Richard, 2004. 
MAPA N¹. ESQUEMA DE TOPOGRAFÍA DE LA CIUDAD DE TEMUCO

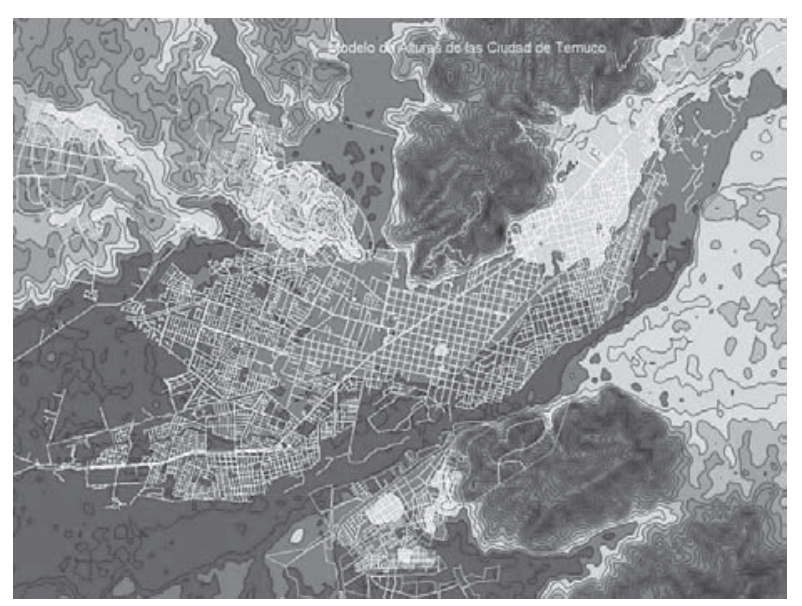

FUENTE: DEM elaborado por Instituto de Estudios del Hábitat, Facultad de Arquitectura, Universidad Autónoma de Chile.

\section{MAPA N². NÚMERO DE BICICLETAS POR MANZANA, AÑO 2002}

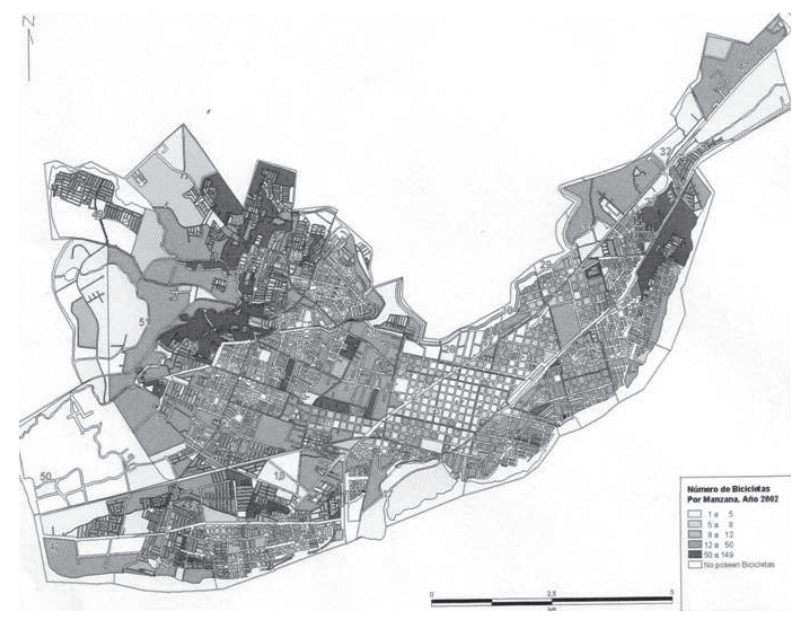

FUENTE: SECTRA, Diagnóstico del Sistema de Transporte Urbano de Temuco, 2002

\section{MAPA N³. ORIGEN Y DESTINO DE LOS VIAJES EN BICICLETA EN TEMUCO}
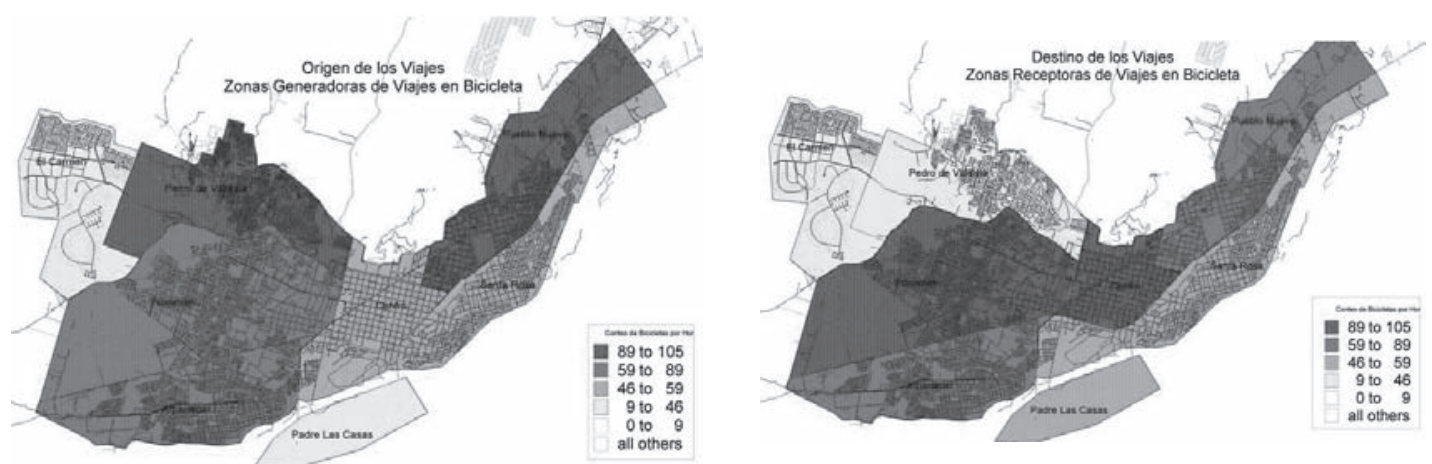

FUENTE: Eltit, Verónica. 2007

172 revista invi № 72 / Agosto 2011 / Volumen № 26: 153-184 
MAPA N4. CICLOVÍAS EXISTENTES EN LA CIUDAD DE TEMUCO

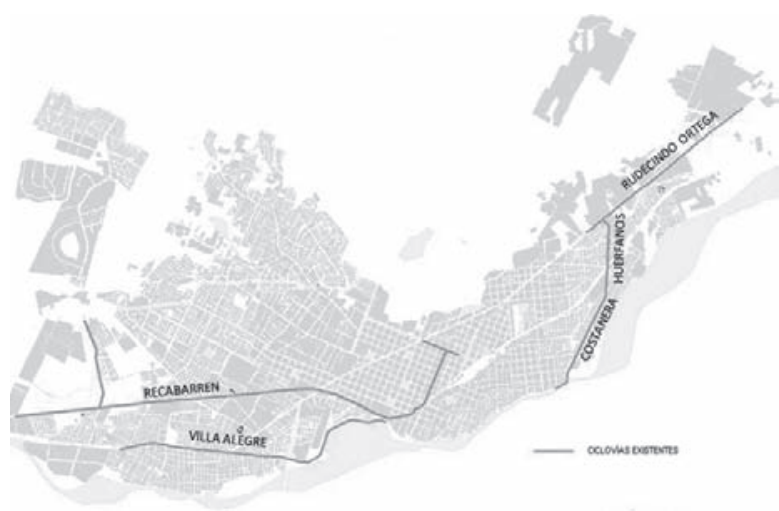

FUENTE: Eltit, Verónica. 2007

MAPA N6. PROPUESTA “RED DE CICLOVÍAS PARA LA CIUDAD DE TEMUCO"

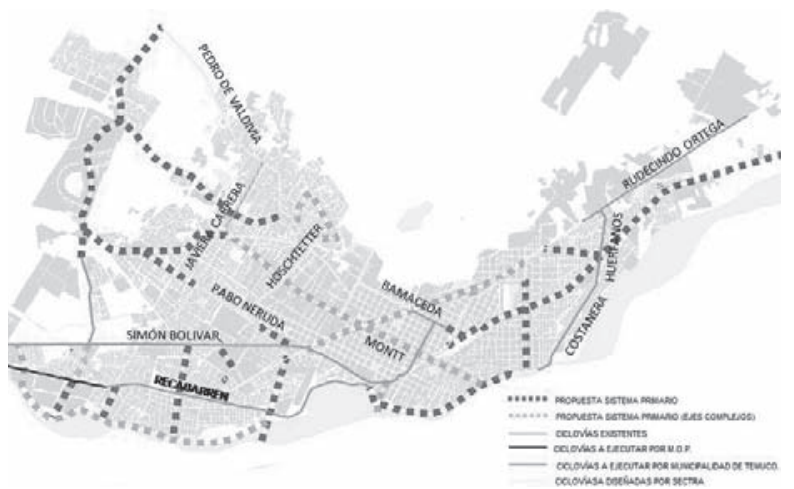

FUENTE: Eltit, Verónica. 2007
MAPA ${ }^{\circ} 5$. CICLOVIAS GESTIONADAS 0 EJECUTADAS POR INSTITUCIONES PÚBLICAS.

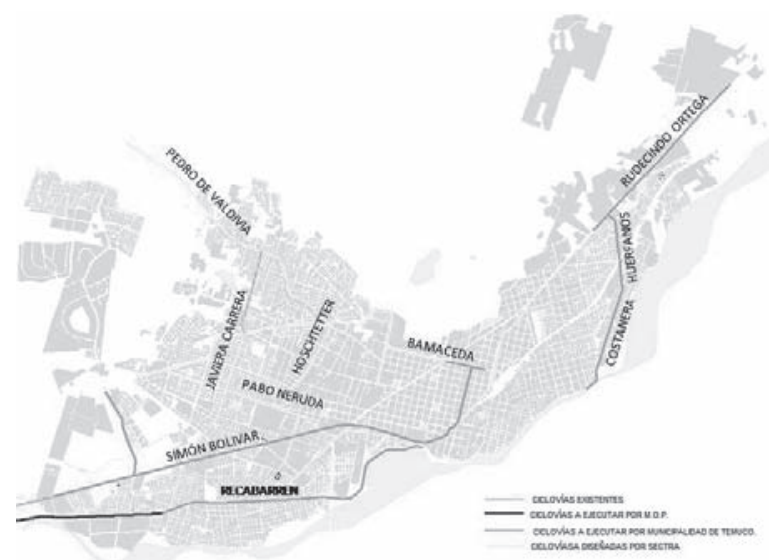

FUENTE: Eltit, Verónica. 2007 


\section{CICLOVÍAS EXISTENTES EN LA CIUDAD DE TEMUCO}

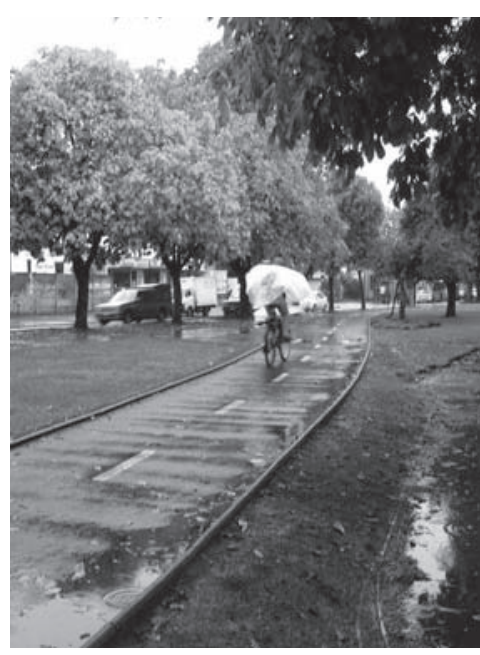

FOTO No 1: Av. Balmaceda.

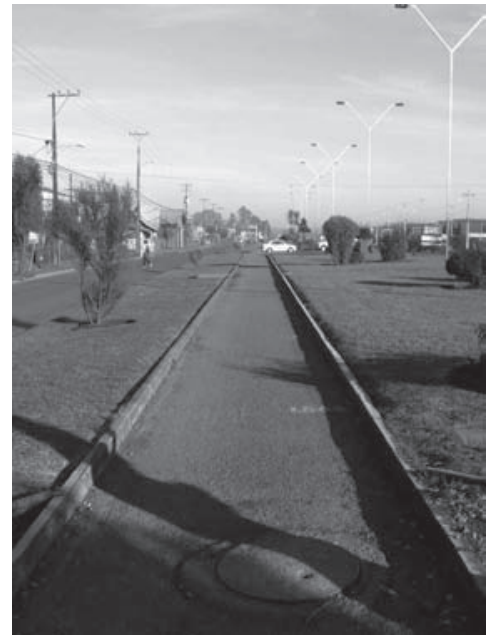

FOTO No 2: Av. Recabarren.

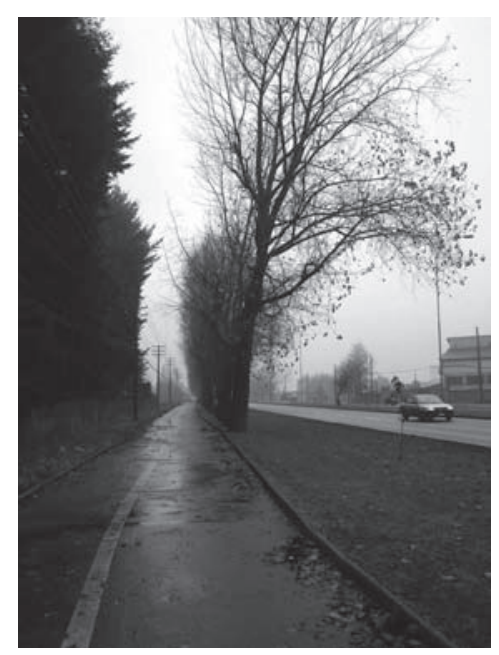

FOTO No 3: Av. R. Ortega.
En muchos países el sedentarismo y la obesidad se han transformado en un grave problema a raíz de la adopción de modelos de conducta extranjeros, donde se privilegia la comida rápida y poco nutritiva, la transformación del mall en la plaza pública, donde la población ya no desarrolla actividad física como parte de su vida cotidiana. Por otro lado, para una persona que no practique una actividad física con regularidad, el riesgo de afecciones coronarias alcanza el mismo nivel que el de un fumador que consuma 20 cigarrillos al día ${ }^{17}$. La

17 BERRíOS, Ximena, Universidad Católica de Chile, 2002 bicicleta, que es tan benéfica como la natación, es mucho más fácil de practicar a diario, pues no obliga a reservar una franja horaria especial, el equipamiento público necesario (las calles) ya existe en todas partes, y solo requiere algunas adaptaciones y su valor es mucho más reducido que la mayoría de los deportes.

Un estudio realizado en Washington ${ }^{18}$, con 600 hombres y mujeres de 18 a 56 años que efectúan al menos cuatro días por semana un desplazamiento

18 CYCLING, 2005 
en bicicleta en distancias de $16 \mathrm{~km}$ (ida y vuelta) o más, puso de manifiesto que los ciclistas tienen una salud física y psíquica mejor que los que no lo son. Se observa un índice de afecciones cardíacas de tan solo un 42,7 por mil, frente a un 84,7 por mil en los no ciclistas (las enfermedades cardiovasculares son una de las principales causas de mortalidad en nuestro país) $)^{19}$.

También se detectó una disminución notable en los ciclistas de hipertensión, bronquitis crónica, asma, afecciones ortopédicas, enfermedades de las glándulas sebáceas y varices de las extremidades inferiores. El estudio pone de manifiesto que la probabilidad de que los ciclistas se consideren "felices" o "muy felices" es cuatro veces superior que en el caso del grupo de control.

\section{Ciclovías}

Ciclovía, ciclorruta, bicicarril, carril bici o bicisenda es el nombre genérico dado a parte de la infraestructura pública u otras áreas destinadas de forma exclusiva o compartida para la circulación de bicicletas. La ciclovía puede ser cualquier carril de una vía pública que ha sido señalizado apropiadamente para este propósito, o una vía independiente donde se permite el tránsito de bicicletas. ${ }^{20}$
Conforme a la definición de la Ordenanza General de Urbanismo y Construcción (Chile, 1992), la ciclovía es una vía destinada exclusivamente al tránsito de vehículos menores, tales como bicicletas, motos de baja cilindrada, triciclos y otros, cuya característica puede corresponder a la de ciclopista o de ciclobanda.

Es imprescindible que cualquiera de estos espacios se dote de la señalización vertical, demarcación, soleras y dispositivos viales que sean necesarios para separar las superficies de desplazamiento de los peatones y vehículos motorizados de las destinadas a bicicletas, logrando el respeto mutuo de todos los usuarios de la vialidad tanto urbana como rural.

Cuando se habla de "medidas favorables a la bicicleta" se suele pensar en las que contribuyen a facilitar los desplazamientos en bicicleta. Sin embargo, el principal elemento a desarrollar se refiere al concepto de red, el que se desarrolla, planifica y construye como parte del sistema integral de vías, de modo de hacerlas coincidir en algún tramo, partiendo de la base de las ciclovías ya existentes, creando así una malla.

A medida que se construyan ciclovías y se conecten con las ya existentes se irá formando una red ciclovial lo suficientemente densa, de manera

19 STANDFOR, Richard, 2004

20 Federación Europea de Ciclistas, revista N²1, 2002. 
que sea posible atravesar el área de estudio completamente de norte a sur y de oriente a poniente. Esto se conseguirá solo si se utilizan todas las herramientas de diseño vial necesarias para que el desplazamiento sea de forma segura y constante dentro de la red. Cuando se ha establecido un plan de red, basta un instrumento de control para garantizar que, cada vez que se programan las obras, se incluya la realización de los acondicionamientos deseados para bicicletas, por ejemplo al Plan Regulador Comunal.

Dentro de estos sistemas, se definen tres tipos de ciclovías:

Ciclovía Exclusiva: pista de dedicación exclusiva, separada por un espacio abierto o una barrera de las vías de automóviles.

Ciclovía Incorporada: pista que forma parte de una vía automovilística, pero que ha sido separada de ella por medio de un elemento especial de marcación en el pavimento.

Vía Compartida: solución de pista para bicicletas solo separada de los automóviles mediante una línea pintada. Es común por su facilidad de implementación, pero altamente peligrosa. Normalmente es compartida con peatones y motocicletas. ${ }^{21}$

Bajo este escenario, desde el año 2002 en Temuco el Ministerio de Obras Públicas, la Secretaria Na- cional de Tránsito y la Municipalidad de Temuco, entre otras instituciones públicas, se han abocado a la construcción de pequeños tramos de ciclovías al interior de la ciudad. El primero fue el existente en la Av. Recabarren, siguiendo con la Av. Rudesindo Ortega en la entrada norte de la ciudad y, finalmente, en la Av. Balmaceda, en el sector de la Feria Pinto y antigua estación de trenes. Sin embargo, estos tramos no tienen ninguna interconexión entre sí o con el resto de la ciudad, por lo tanto su uso es mínimo. De ahí la importancia del diseño de un sistema de red para toda la ciudad, que permita planificar la ubicación de estas vías en forma coherente.

A la fecha, en la ciudad de Temuco hay más de $26 \mathrm{~km}$. lineales de ciclovías construidas en los ejes detallados en la tabla No8.

En un comienzo estas ciclovías no eran muy utilizadas por su corta distancia y ubicación, porque no conectaban ningún punto relevante de la ciudad y además no estaban insertas en una red que las interconectara con otras. Sin embargo, a raíz de la alta solicitud por constituir el sistema de ciclovías y por el fomento al desarrollo de estas que se está impulsando desde el gobierno central hacia las regiones (ministerios, servicios públicos, etc.), se están desarrollando variadas iniciativas de proyectos para el desarrollo de ciclovías para Temuco,

21 HARRISON \& SWAIN, 1999 
las que se construirían dentro de los próximos 5 años. Los trazados propuestos están detallados en la tabla $\mathrm{N}^{\circ} 9$.

Considerando las diversas iniciativas lideradas por variadas instituciones sin mayor coordinación, se desarrolla una propuesta de "Red de Ciclovías para la ciudad de Temuco" como parte de una investigación desarrollada durante el año 2007, donde además se analizan las características del usuario, tipos de viajes, motivos de viajes, etc., en base a un trabajo de campo que consideró, entre otros, entrevistas, encuestas, fichas de registro y conteo de bicicletas en puntos estratégicos de la ciudad. Si bien esta información fue levantada y procesada por medio de un trabajo académico entre los años 2008 y 2010, el equipo técnico de planificación de la Municipalidad ha utilizado este instrumento para la elaboración de los planes y programas antes mencionados, logrando la concreción de infraestructura asociada al uso de la bicicleta en relación a proyectos viales, de espacios públicos y recreación.

La propuesta, presenta dos escalas de complejidad y priorización para el desarrollo de ciclovías:

a) Sistema de Ciclovías Primario: La escala de este sistema tiene relación con toda la ciudad, e incluso podría llegar a ser comunal o intercomunal (si consideramos la conexión con Labranza, Cajón y Padre las Casas). Genera una malla de cuadrantes, donde las ciclovías son parte de un perfil vial, incorporándose en alguna de las áreas verde laterales o centrales dependiendo del perfil existente y, de lo contrario, en el borde de la calzada separando los flujos con algún elemento sobresaliente (tachón, solera, solerilla, etc.).

El sistema propuesto primero rescata las propuestas de ciclovías que se están desarrollando, pues aunque su implementación no ha sido ni consensuada ni planificada, es importante concretar aquellas iniciativas que ya han logrado apoyo político y, en especial, financiamiento en sistema que es complejo y largo ( 3 a 4 años entre la presentación de la iniciativa hasta la construcción de esta, cuando se ha logrado el apoyo político y el adecuado desarrollo técnico). Después, se proponen 10 trazados sobre ejes viales en diferentes tramos, con características que permitan la incorporación de una ciclovía como:

a. Integrador de Zonas Segregadas;

b. Carácter de Espacio Público;

c. Interconexión de Zonas Funcionales;

d. Conexión Intercomunal;

e. Asociación a Elementos Naturales;

f. Nivel de Pendiente;

g. Elementos Existentes (arborización, postación);

h. Capacidad de Gestión (implementación, expropiaciones, etc.); 
i. Nivel de seguridad;

j. Proyectos Asociados;

k. Cabida en el Perfil Existente.

b) Sistema de Ciclovías Secundario: el desarrollo integral implica el estudio, análisis y diseño de las calles, espacios públicos y veredas de todos los cuadrantes resultantes del Sistema Primario. La propuesta corresponde a una escala barrial, donde el diseño no solo pasa por incorporar una ciclovía, sino a toda la calle como espacio público, donde los flujos peatonales y de bicicletas son compartidos y los vehículos motorizados se someten a estas velocidades reduciendo su protagonismo. Además, este sistema tiene una proyección de ejecución a mediano plazo, a diferencia del sistema primario.

Dentro de esta propuesta también se analizaron de forma especial algunos ejes que por su alta complejidad (dureza al cambio, morfología, nivel de tránsito, etc.) presentan una probabilidad de mayor dificultad en su diseño, formulación y ejecución, como lo son: Avenida Alemania, principal conexión entre el centro y el sector poniente de la ciudad; Avenida Caupolicán, que cruza la ciudad en diagonal desde el acceso norte hasta el acceso sur; y la calle General Mackenna, que enlaza con el puente de interconexión con la comuna de Padre las Casas.

\section{Una política de la bicicleta}

Hasta ahora las medidas adoptadas en relación al uso de la bicicleta están relacionadas con aspectos de carácter técnico en el desarrollo de infraestructura. Pero ninguna política de fomento del uso de la bicicleta tendrá éxito si solo se aborda la implementación de ciclovías y no se acompaña de campañas de promoción de la bicicleta organizadas por las autoridades públicas, que informen adecuadamente a la población de los beneficios que esta genera y la infraestructura que la ciudad brinda para el adecuado uso de la bicicleta.

Además, para una adecuada implementación de cualquier política, ideal es contar un modelo de gestión que, entre otros factores, considere un presupuesto determinado. Sin embargo, algunas ciudades han aplicado su política de la bicicleta (o, al menos, la han iniciado) sin contar con un presupuesto específico, como es el caso de Temuco, siendo así que todo lo que se hace en lo que se refiere a acondicionamientos para bicicletas se ha integrado en la programación de las obras viales, desarrollo de parques temático y en el presupuesto general.

Como parte del modelo de gestión es imprescindible incorporar a los privados en el tema, tanto en el financiamiento de la implementación y manteni- 
miento de la ciclovías como en el fomento del uso de la bicicleta en la ciudad. El sector privado puede intervenir de varias maneras. Hay que dirigirse a las empresas locales e incitarlas a propiciar el uso de la bicicleta por parte de sus empleados, desarrollando actividades como campañas informativas, instalación de estacionamientos con duchas y vestuarios, concesión de ventajas materiales a los empleados que utilicen la bicicleta para su desplazamiento diario de casa al trabajo y que permiten ahorrar la inversión en plazas de estacionamiento.

En este contexto, los beneficios que tienen el comercio y las empresas en relación a los usuarios de la bicicleta son numerosos. Primero, considerando que los ciclistas son personas en mejor forma física y, sobre todo, psicológica, las empresas cuyo personal utiliza la bicicleta registran una mayor productividad $^{22}$.

En este sentido, hay experiencias de empresas internacionales y nacionales que han desarrollado mecanismos de incentivo para sus trabajadores para ir al trabajo en bicicleta. Por ejemplo, el ofrecimiento de bicicletas nuevas a empleados que estén dispuestos a renunciar a sus plazas reservadas en el estacionamiento de la empresa. Organización de jornadas dedicadas a la bicicleta, con recorridos, información y talleres de reparación. Es así como las ventajas son múltiples: ahorro de estaciona-

22 European Cyclist, Boletín Informativo Nº 35, 2006 mientos, descongestión de las calles próximas a la empresa, una mejor imagen de marca para los residentes y las autoridades, mayor movilidad para los empleados, que, además, se mantendrán en mejor forma física, con la consiguiente reducción de las ausencias laborales por enfermedad ${ }^{23}$.

Por otro lado, si analizamos la ecuación "vitalidad del comercio = acceso en automóvil", esta dista mucho de estar demostrada por los hechos. La contribución de la clientela que accede mediante el transporte público, la bicicleta y a pie se ha subestimado considerablemente, al igual que el impacto negativo para nuestras ciudades y para el entorno urbano de la implantación de grandes empresas de distribución y de miles de plazas de aparcamiento en la periferia.

En algunas categorías los ciclistas son, incluso, mejores clientes. Compran menos cantidad por visita, pero van a comprar con más regularidad (once veces al mes por término medio, frente a siete veces en el caso de los automovilistas), y por lo tanto están más expuestos a la tentación ${ }^{24}$.

Bajo este mismo modelo de gestión, las autoridades locales pueden colaborar al fomento por medio de incentivos económicos o rebajas tributarias que permitan priorizar la bicicleta por sobre el automóvil. 
Por ejemplo, la industria de la bicicleta y los vendedores y talleres de reparación pueden financiar un mapa para ciclistas o una carpeta informativa mediante la compra de espacios publicitarios. Pero existen otras posibilidades, como el patrocinio de paneles de señalización (mediante marcas o flechas), publicaciones por parte de las compañías de seguros o los bancos, de cursos de formación sobre el tema "en bicicleta al colegio" por una editorial o un productor de material escolar, de un mapa para ciclistas por una editora de mapas de carreteras (como Turistel), estacionamientos o bicicletas de alquiler delante de los negocios y en los paraderos del transporte público con anuncios publicitarios, etc.

En este mismo sentido, en la ciudad de Temuco existen más de 10 instituciones de estudio superior, generando una población estudiantil de más de 60.000 jóvenes, quienes clasifican como un usuario potencial prioritario. Es así, como estas organizaciones deben ser parte primordial de cualquier campaña de fomento del uso de la bicicleta, idealmente en forma coordinada, para generar conciencia tanto en la ciudadanía como en la autoridades de la masa crítica existente y las potencialidades que brinda la ciudad para este mecanismo de transporte.
180 revista invi № 72 / Agosto 2011 / Volumen № 26: 153-184
Así mismo, el transporte de escolares en auto puede representar hasta un $30 \%$ de los desplazamientos en horas punta de la mayoría de las ciudades de nuestro país ${ }^{25}$, y por supuesto en Temuco también.

No obstante, cerca del $50 \%$ de los escolares manifiestan que su medio de transporte preferido para ir al colegio sería la bicicleta. Teniendo en cuenta que las distancias entre el domicilio y el centro escolar suelen ser inferiores a $3 \mathrm{~km}$. (es decir, unos 10 minutos en bicicleta), se debería satisfacer más a menudo un deseo tan saludable. Los jóvenes manifiestan así su deseo de ejercer una parte de autonomía e independencia, y los niños de 13-14 años son un grupo destinatario muy destacado ${ }^{26}$. Si a esto le sumamos el incremento de la obesidad infantil en Chile, donde ha aumentado en los últimos 10 años de un 13\% a un 22\% en hombres y de $20 \%$ al 39\% en mujeres ${ }^{27}$, tenemos que la bicicleta es una forma de incentivar la actividad física de forma entretenida y económica.

Si se convierten los centros escolares en destino de los itinerarios o los acondicionamientos para bicicleta y se aplican medidas complementarias, como la seguridad de la bicicleta en destino y una labor de información a los padres y de formación de los niños, las inversiones realizadas darán, con seguri-

25 Encuesta Origen Destino, SECTRA, 2005.

26 Ane Lowe, 2003 Comité Pro Bici, 2003.

27 Ximena Berrios, Depto. de Salud Pública de la Pontifica Universidad Católica de Chile 
dad, fruto inmediato en términos de utilización. El uso de la bicicleta es una buena manera de inducir a los jóvenes a hacer ejercicio todos los días.

Varios estudios han puesto de manifiesto que el hábito de practicar actividades físicas se crea esencialmente durante la formación escolar. En Estados Unidos, donde la dependencia del automóvil es extrema, uno de cada cinco niños padece obesidad por falta de ejercicio físico, y el $33 \%$ del total de la población padece obesidad (frente a un 10\% en Europa y un 20\% en Chile) ${ }^{28}$.

Un estudio realizado en el Reino Unido ${ }^{29}$ demuestra que el ejercicio físico aumenta la densidad ósea, reduciendo los riesgos de fractura en la edad adulta. La duplicación del número de fracturas del cuello del fémur durante los 30 últimos años se debe principalmente, al parecer, a una fuerte disminución de las actividades físicas para la media de la población del Reino Unido.

En respuesta a este fenómeno, en el Reino Unido, para incitar a los padres a permitir a sus hijos ir en bicicleta al colegio, algunos colegios organizan un "transporte escolar" en bicicleta: con la ayuda de padres o profesores voluntarios, organizan itinerarios a lo largo de los cuales un adulto recoge a un máximo de 5-7 niños para trasladarlos desde el centro educacional hasta sus hogares ${ }^{30}$.
La organización de cursos de formación para los niños de poca edad tiene el mismo objetivo: garantizar la seguridad de los niños y tranquilizar a los padres, estrategia de simple y económica implementación, en especial en las escuelas municipales donde las redes sociales ya están consolidadas.

\section{Conclusiones}

Sin duda, la bicicleta se presenta como un sistema sustentable de circulación urbana; sin embargo, el éxito de su aplicabilidad en la diferentes ciudades dependerá de la forma en que se logre incorporar a un sistema tan complejo como lo es el sistema vial urbano.

Pero, si se logra enfocar entendiéndolos como sistemas complementarios, se puede visualizar que, si bien las ciclovías son vías públicas de uso específico de un medio de transporte (la bicicleta), en la mayoría de los casos estas adquieren carácter de espacio público, pues están asociadas a áreas verdes, elementos naturales relevantes en la estructura urbana o parques. O sea, son el espacio intermedio y muchas veces articulador entre la calle, como zona de apropiación de los vehículos motorizados (sistema vial), y las veredas, como zonas peatonales. Muchas veces es la amortiguación

28 Comité Pro Bici, 2003.

29 Baden, Poulsen, Godefrooij \& Eritja, 1998

30 National Cycle Network y Safe Routes to School, 1995 
entre dos zonas que no pueden ser compatibles por flujos, velocidades y formas de uso; sin embargo, una ciclovía bien diseñada podría disminuir ese impacto, haciendo el sistema vial de la ciudad más agradable para el peatón y complementando el sistema vial existente.

El carácter de espacio público que adquieren las ciclovías hace imprescindible un proceso de participación ciudadana que permita validar el análisis técnico aquí realizado. Esta participación debiera involucrar tanto a autoridades locales como a actores relevantes de organizaciones sociales y ciudadanas, así como a los involucrados, o sea los ciclistas, y por otro lado a las personas que se vean afectadas por las vías a intervenir, con el fin de invertir de manera pertinente y construir modelos innovadores en casos críticos.

En el caso específico de Temuco, se analizan ventajas comparativas para el uso de la bicicleta como medio de transporte urbano. Por un lado la escala de la ciudad, que propicia traslados promedios de $3 \mathrm{~km}$. aproximadamente, lo que permite movilizarse fácilmente dentro de la ciudad; por otro lado la geografía, principalmente plana (exceptuando zonas específicas de la ciudad como el sector de Pedro de Valdivia), y finalmente una población estudiantil importante que cuentan con las características ideales para la aplicación de políticas de fomento del uso de la bicicleta (edad, estado físico, interés, entre otros).
Actualmente se están desarrollando variadas iniciativas de ciclovías en la ciudad de Temuco, a cargo de diferentes servicios públicos. Si bien ya se cuenta con un instrumento que ha planificado un trazado de "Red de Ciclovías para Temuco", su falta de validación y apropiación no ha permitido la coordinación entre las entidades ejecutoras y posibles financistas. Por eso, es importante la definición de un trazado consensuado por todos los actores involucrados, para que cada vez que alguna institución deba realizar alguna iniciativa relacionada con ciclovías exista la información necesaria para poder definir los diseños, localizaciones y trazados más adecuados para cada vía.

Además, esto permitiría poseer una visión clara al momento de postular a financiamientos para el desarrollo de algún proyecto vial, el que desde un principio debiera incorporar la ciclovía como parte del perfil a construir o remodelar.

Por otro lado, la definición del usuario de la bicicleta lograda en relación al proceso de encuestas y fichaje de la investigación base, define como primera prioridad de desarrollo aquellas ciclovías que permitan dar solución a las personas que transitan actualmente en bicicleta para acceder a las fuentes laborales, especialmente por un tema económico. Estas rutas deben ser directas, expeditas e interconectadas, para que el sistema responda a las necesidades de movilización de los usuarios en cuestión. 
Finalmente, tan importante como el desarrollo de la infraestructura adecuada, es el desarrollo de una política general de la bicicleta, que permita aplicar medidas, gestiones y coordinaciones para:

a) La difusión del trazado consensuado de ciclovías de la ciudad;

b) Educación sobre el buen uso de las ciclovías;

c) Educación sobre el uso responsable de la bicicleta;

d) Programas de fomento del uso de la bicicleta en instituciones públicas, privadas, sistemas escolares, organizaciones de estudios superiores, entre otros;

e) Educación sobre el respeto desde el conducto motorizado hacia los ciclistas.

\section{Referencias bibliográficas}

AKIKI, Natalia. Informe Preliminar del Diagnóstico para la planificación estratégica de la inversión en infraestructura vial para la ciudad de Temuco. Chile, Secretaría Nacional de Transporte. 2006.

BORAS, L. Pacto andaluz por la bicicleta. En: GUíA de diseño paraespacios públicos. MINVU. 2002 p. 1-2.

BOTMA, B. y PAPENDRECH, C. Traffic operation of bicycle traffic. Transportation Research Record (1320): 65-72, 1991.

CHILE. Instituto Nacional de Estadística. Censo 2002. [En línea]. INE censos de población y vivienda.
Disponible en: http://www.ine.cl/canales/chile_estadistico/censos_poblacion_vivienda/censo_pobl_vivi.php

CHILE. Secretaría Nacional de Transporte, Comisión de Planificación de Inversiones en Infraestructura de Transporte. Plan de desarrollo del sistema del transporte urbano de la ciudad de Temuco. Chile, Comisión de Planificación de Inversiones de Infraestructura de Transporte. 1999.

CHILE. Ministerio de Vivienda y Urbanismo. Ordenanza General de Urbanismo y Construcciones D.S. No47 de 1992. [En línea]. MINVU. 2011. Disponible en: http://www.minvu.cl/incjs/download. aspx?glb_cod_nodo=20061113162221\&hdd_ nom_archivo=OGUC\%20Abril\%202011.pdf

CHILE. Secretaría Nacional de Transporte, Encuesta Origen Destino para la ciudad de Temuco. 2005.

CHILE. Secretaría Nacional de Transporte. Manual del uso de la bicicleta. pp. 2-3. 2005.

COMITÉ Pro-bici. El uso de la bicicleta como medio de transporte urbano. [En línea]. Sevilla en Bici. 2003. Disponible en: http://www.sevilla.org/sevillaenbici/contenidos/5-documentacion/entidades/uso_de_la_bicicleta_como_medio_d.htm

CONFERENCIA Mundial sobre la Bicicleta Vélo Mondial. Declaración de Ámsterdam. [En línea]. 2000. Disponible en: http://www.uv.es/DSSQA/ mediambient/documents/DECLARACION\%20 DE\%20AMSTERDAM.pdf

CREATING a chain reaction. The London Cycling Action Plan. London, Transport for London. 2004. 48 p.

revista invi № 72 / Agosto 2011 / Volumen № 26: 153-184 183 
DEKOSTER, J. y SCHOLLAERT, U. En bici, hacia ciudades sin malos humos. [En línea]. Comisión Europea. 2002. Disponible en: http://ec.europa.eu/ environment/archives/cycling/cycling_es.pdf

ELTIT, Verónica. Impacto de la globalización en ciudades intermedias: el caso de Temuco, Región de la Araucanía. Universidad Autónoma de Chile. 2003. Seminario para optar al grado de licenciado en Arquitectura.

--_. Propuesta de red de ciclovías para la ciudad de Temuco. Universidad de la Frontera. 2007. 174 h. Tesis para optar al grado de Magíster en Planificación Territorial Ambiental.

FEDERACIÓN de Ciclistas Europeos. En bicicleta al trabajo beneficios claros para todos/as. [En línea]. Sevilla en Bici. 1998. Disponible en: http://www. sevilla.org/sevillaenbici/contenidos/2-hazlobien/ ventajas/en_bicicleta_al_trabajo_benefici.htm

KOMUNICA Producciones y Geosafe. Estudio promoción del uso de la bicicleta. [En línea]. Proyecto Calidad del Aire y Transporte Sustentable para la Ciudad de Santiago de Chile. 2006. Disponible en: http://catss.sectra.cl/Tallerl/Download/exposiciones/ciclovias/Promocion/Estudio_Promocion_Uso_Bicicleta.ppt

PLANIFICACIÓN e implementación de campañas destinadas a promover el uso de la bicicleta en países de América Latina. Guía para tomadores de decisiones. [En línea]. NESTLAC. 2009. Disponible en: http://nestlac.org/Publicaciones/Planificacion \&ImplementacionUsoBicicletaAmericaLatina.pdf
SASSEN, Saskia. A global city. En: NUGENT, David (ed.); VINCENT, Joan (ed.) A companion to the anthropology of politics. Malden, MA, Blackwell. 2004. ISBN 9780631229728.

. Global cities and developmentalist states: how to derail what could be an interesting debate: a response to Hill and Kim. Urban Studies. 38(13): 2537-2540, 2001. ISSN: 1360-063X. Disponible en: http://www.columbia.edu/ sjs2/PDFs/Response\%20to\%20Hill\%20Kim.2001.pdf

STEER Davies Gleave. Programa de fomento al uso de la bicicleta en las comunas de Santiago, Providencia y Nuñoa, transporte sustentable y calidad del aire para Santiago. [En línea]. Ciudad Viva. 2006. Disponible en: http://www.ciudadviva.cl/sitio/ index.php?option=com_docman\&task $=$ doc_ download\&gid $=423 \&$ Itemid $=69$

THE EUROPEAN Network for Cycling Expertise. Cycling and promotion. [En línea]. Alliance for Biking and Walking. (s.f.). Disponible en: http:// www.peoplepoweredmovement.org/site/images/ uploads/Cycling_Promotion.pdf

THOMSON, Ian. Transporte sostenible en las ciudades de América Latina. [En línea]. CEPAL. 2000. Disponible en: http://www.eclac.org/Transporte/ capacitacion/8/5728/Thomson.doc

TRASA Ingeniería. Estudio de factibilidad vial para la ciudad de Temuco para el diseño del Plan Regulador Comunal. [En línea]. Chile, Ministerio de Vivienda y Urbanismo. 2001. Disponible en: http:// www.temucochile.com/planregulador/04_Estudios/Estudio_de_Factibilidad_Vial/Estudio_Factibilidad_Vial_FINAL.pdf 